\title{
From Inclusion to Creativity Through Haptic Drawing: Unleashing the "Untouched" in Educational Contexts
}

\author{
Matthew Kirby and Amedeo D’Angiulli*
}

Institute of Interdisciplinary Studies \& Department of Neuroscience, Carleton University, Ottawa, Ontario, Canada

\begin{abstract}
Haptics, or the sense of active touch, is an underused modality in educational contexts. In this paper, we review current literature regarding the development of haptic processes and the underlying neurocognitive mechanisms. On the basis of previous research, we argue that exposure and guidance can increase the ability of individuals to employ haptic processes by recruiting areas of the visual cortex that are normally employed for visual processes, a process known as cross-modal plasticity. Cross-modal plasticity provides a plausible account for the counter-intuitive creativity displayed by blind individuals in producing drawings. We propose that further implementation of haptics in education may be used to promote creativity and inclusion, as well as facilitating other processes required for learning in educational settings. In particular, haptic drawing could be generalized as a tool for inclusive education to promote and enhance creativity at any age through cross-modal neurocognitive plasticity in students with and without visual impairment.
\end{abstract}

Keywords: Haptic drawing, cross-modal plasticity, creativity, blindness, inclusive education.

\section{INTRODUCTION}

"...how fundamentally important it is for teachers to realise that the nature of creative expression is bound up with haptic perception whenever this is the artist's basic and habitual mode of experience."

(Lowenfeld, 1952; p.84)

As the only sense that allows us to modify and manipulate the physical world [1], our sense of touch plays a profound role in shaping our perception of and interactions with our environment. Routine tasks, such as searching for something in a pocket or turning on a light in a darkened room, and highly valued professional skills, such as repairing machinery or performing surgery, heavily rely on the sense of touch. Touch provides the foundation for understanding the basic physical principles of friction, resistance, force, and impenetrability [2]; furthermore, touch provides details about other physical properties including size, shape, distance, texture, and elasticity [3]. Yet, compared with sight perception, the sense of touch is an area that is underrepresented in research on education and creativity despite its importance in everyday life [3-5].

Originally coined by Revesz [6], the word haptics is now used to describe anything related to the sense of active touch (i.e., tactual feedback plus movement) and the corresponding field of research. Due to the diverse range of tasks that require or make use of our sense of touch, the field of haptics is ostensibly multidisciplinary and involves research in various subjects including psychology, neuroscience, cognitive science, engineering, computer science, and

*Address correspondence to this author at the Institute of Interdisciplinary Studies \& Department of Neuroscience, Carleton University, 1125 Colonel BY Drive, Ottawa, ON, K1S 5B6, Canada; Tel: (613) 5202600 2954; Fax: (613) 520-3985; E-mail: amedeo@connect.carleton.ca robotics [3]. As such, discoveries in the field of haptics could potentially have a strong and wide reaching impact. A growing body of evidence indicates that the field of education may be among the foremost beneficiaries of haptics research and applications.

Arnheim [7] suggests that haptic exploration is the sensory modality most closely linked to dynamic perception, the basis of aesthetic experiences, and that tangibly perceiving the interaction between space and shape allows for the effective conveyance of expression. This means that the primary sensory modality employed by blind individuals may predispose them for artistic cognition. Contrary to this concept, drawing, painting, and sculpture are generally considered visual arts. In fact, many maintain the viewpoint that in the absence of sight, pictures are useless [5]; as such, blind individuals are given limited access and exposure to pictures [8-10], and even less access and exposure to haptic drawing tools $[11,12]$. As will be discussed, the implementation of haptic educational strategies can lay the foundation for conducting inclusive classes that allow all students, regardless of their ability to see, to actively engage in the material and provide a medium for creative thought and expression.

In this paper, we review research related to the underlying mechanisms of haptic processing that are pertinent to education and creativity, and we discuss the potential benefits and applications of haptics to foster inclusion and creativity in an educational setting, namely: the development of haptic processes as an individual matures; the enhancement of haptic processes with experience and guidance; the ability of the blind to draw using haptic processes and tools; the underlying mechanism that can explain the ability of the blind to draw and produce creative works, i.e. cross-modal plasticity; the perceptual foundations of creativity in haptics and vision; utilizing haptics in educational settings to promote inclusion for the betterment of all students; and finally, the application of 
haptic processes to enhance learning and memory through the same core mechanisms underlying creative generativity in this modality. Our central thesis is that through activities linked with an underused modality, such as haptic drawing, not only can educators promote inclusion but also creativity in all individuals, visually impaired or not.

\section{HAPTIC PROCESSING AND AGE}

Touch, and by proxy haptic processing, serves an essential function in human development. The sense of touch mediates our ability to perceive how the environment physically acts on us, and how we physically act on the environment and ourselves [3, 13]. Early research has suggested that haptics, as the primary sensory modality in the early stages of childhood development [3], is the principal means by which children acquire information about their environment; information that contributes to a child's understanding of their environment and facilitates the construction of organizational action schemes $[14,15]$. This concept is supported by more modern research that has illustrated the importance of the role haptics play in the acquisition, retention, and recall of memories related to salient physical properties of an object, including shape, weight, size, substance, and volume [3, 16-18].

Although there are some key differences between haptic processing in adults and children, research suggests that young children and adults employ haptics processes for the same purposes. Klatzky, Lederman, and Mankinen [19] examined children ranging in age from 3 years and 11 months to 4 years and 11 months, and their process for evaluating the various features of objects. The children were presented with pairs of objects whose attributes contrasted in five distinct measures: shape, weight, roughness, and hardness. When each pair of objects was presented, the children were asked to judge which of the two items was greater in one of the given measures. The children were instructed that they could look and touch the objects, but were not required to touch. The results of this study demonstrated that children will employ the same senses as adults would to determine certain physical traits: they primarily used sight to determine size and shape, they lifted the objects to compare weight, and determined hardness by pressing or pinching the objects. The authors drew the conclusion that the "children tended to explore as adults would" [19, p. 247]. Though this demonstrates an important similarity between children and adults regarding their exploratory processes, there are some important differences that indicate how haptic processing becomes more effective as individuals age.

Haptics serve as the primary sensory modality in early childhood and remain important throughout the lifetime; as such, it is unsurprising that strategies to optimise the effectiveness of haptic processing are naturally developed as an individual matures. Research has found some significant differences between the procedure employed by children and adults in acquiring haptic information. In a study by Berger and Hatwell [20], child and adult populations were evaluated in terms of haptic strategies of comparison. The subjects of this study were presented with cubes varying in hardness and texture, to be examined only by touch. The subjects were first presented with a cube, then shown 3 more cubes, and asked to find which cube "goes best with" the original cube.

The results of this study showed that, in making their selections, children tended to rely more on hardness, whereas adults tended to make their selections according to texture. More importantly, it was found that children were less likely to respond based on the overall similarity of the objects, as adults generally did; instead children tended to focus on individual properties. Berger and Hatwell suggested that children haven't systematically organized their process of exploration, resulting in an incomplete perception of the object. In contrast, adults employ a systematic process of exploration that provides them with enough information to construct a "global" cognitive representation of the object [20].

The results of Berger and Hatwell's study support the notion that adults have developed exploratory procedures that facilitate the assimilation of information. These exploratory procedures, which are believed to allow for greater ease of encoding, include: sensing through pressure, to observe hardness; following the contour, to observe volume and shape; and lateral movements, to detect texture through friction [21].

As one would expect, not only does research show that haptic exploratory procedures naturally develop over the lifetime, but experience and training with haptic processes can help determine the extent of that development [22]. Further studies that have observed and drawn comparisons between individuals with and without visual impairments lend incite into the potential development of enhanced haptic processes.

\section{IMPROVING HAPTIC PROCESSES}

\section{Exploratory Procedures}

The field of visuo-haptic research has revealed fundamental similarities in picture processing by means of vision and haptics [23]. In vision, picture recognition seems to be an effortless, automatic and innate ability [e.g., 24]. In touch, picture recognition is much more difficult than in vision, as documented by recognition rates as low as $10 \%$ in adults [e.g., 25]. However, most studies have not properly considered variables such as exposure to pictures and practice as well as guidance to systematic haptic exploration.

Research on blind and sighted children has shown a functional relationship between haptic picture recognition and tactual exploratory skills. Pathak and Pring [26] reported that in an experiment involving raised-line pictures, children who were blind were significantly more accurate than blindfolded sighted children in choosing the correct target picture in a series. Similar findings have been reported in adults by Shimizu, Saida and Shimura [27].

Naturally, those who have more experience are more likely to have better abilities at picking out the relevant cues in a picture and making their exploratory movements of a picture [22]. With regard to sighted populations, research has shown that performance in haptic tasks can be greatly enhanced with some systematic guidance.

D'Angiulli, Kennedy, \& Heller [28] reported that children who were congenitally blind had higher recognition 
rates for tactual (raised-line) pictures than blindfolded sighted children. Given systematic guided exploration, however, tactual information became highly effective in promoting recognition in the blindfolded sighted children. Indeed, blindfolded children whose exploration was guided by the experimenter not only attained levels of recognition equal to that of the congenitally blind children [28], but subsequent studies also found, they equalled the performance of blindfolded adults [29]. These studies demonstrate another important feature of haptic processes: guidance in exploration helps integrate tactual information efficiently [30].

\section{Haptic Drawing and Blindness}

The ability of the blind to create artistic pieces, generally in the form of sculpture or auditory compositions, has been well documented [31]; however, for various reasons, there has been significantly less art produced by the blind in the form pictorial representations. Interestingly, the lack of abundance in pictorial art produced by the blind is not due to a lack of ability. In fact, Lev-Wiesel, Aharoni, \& Bar-David [32] suggest that individuals who are blind are capable of not letting their blindness interfere with drawing and writing tasks, which are typically assumed to require vision. Given the opportunity, instruction and materials, blind individuals have the ability to produce pictorials that are similar in artistry and proficiency to sighted individuals [e.g., 33-35].

Much like the development of haptic exploratory skills, and most skills for that matter, the extent of the development of haptic drawing skills is at least partially determined by exposure to the materials and practice [22]. In accordance with this principle, a 9-month longitudinal study that documented and evaluated the drawings produced by congenitally blind children found that the children's competence in their ability to draw increased over the nine month period [36]. A follow up analysis of the drawings by D'Angiulli, Miller and Callaghan [37] confirmed the initial results, over the nine-month period the quantity of pictures produced by the children decreased, however the complexity of the pictures increased.

Other research has shown that the ability of the blind to draw is correlated with level of formal educational attainment. A study by Lev-Wiesel, Aharoni and Bar-David [32] included 15 born blind adults (18-25 years) with a range of educational backgrounds from no schooling/illiterate to university levels of education, including only one participant that had previous experience with drawing. The participants were asked to produce self-portraits with pencil and paper which were then ranked by two judges on Malchiodi's [38] developmental stages of drawing. The first stage (scribbles) was represented by the participant who was illiterate, whereas the second stage (basic forms) by the participant who graduated elementary levels. There were three high school graduates representing the third stage of development (comprised of human forms and rudimentary schemata) [39]. Lastly, ten participants with more than 12 years of education represented the sixth stage of drawing development, representing adolescence, which includes the accurate use of perspective, abstract images and great detail [39]. These findings suggest that the level of education may also have an impact on the quality of pictures produced and stage of artistic development.

The studies that have investigated the ability of the blind to draw indicate some important features of haptic processing. Millar notes $[11,12]$ the later stages of development in drawing abilities, denoted by an increase in complexity, may come later for individuals who are blind because they have lacked the opportunities to experiment with drawing materials to develop the skills needed to understand how to represent 3D concepts. The amount of practice with and exposure to haptic drawing materials that individuals have is directly related to their level of competence in drawing; this is analogous to the previously discussed development of haptic exploratory procedures with exposure and guidance. Although this relationship seems obvious, it is particularly salient when considering the benefits of implementing haptics in educational contexts. Furthermore, the fact that the development of haptic drawing skills is correlated with education suggests a similar exposure and guidance effect; that is, exposure and guidance with regard to concepts (i.e., geometry, and 3D representations) rather than materials. The fact that congenitally blind individuals are able to identify and create relatively complex images and geometrical patterns, skills that would seem inherently visual, suggests that the underlying principles of mental imagery are inter-modal [36].

\section{Cross-Modal Plasticity}

Early-blind persons can recruit the visual cortex to enhance tactile processing for fine haptic discrimination tasks that usually recruit only sensorimotor areas of the brain in individuals who have late blindness or less severe forms of visual impairments. This form of cross-modal plasticity, where visual cortical areas become reorganized at a neural level to enhance tactile processing, seems responsible for sharpened perceptual learning and memory in individuals who become blind early during development [40-42].

Dulin and colleagues [42] report that vision may be the primary modality of picture perception; however, without it, haptics can access spatial representations through sources such as long term memory. Similarly, blind children have higher recognition memory for previously explored raisedline pictures compared to sighted children, suggesting that cross-modal plasticity enables strategies that make up for the lack of vision [41]. In accordance with this concept, several neuro-imaging studies have found interactions between haptic and visual systems. Results of research that has used functional magnetic resonance imaging (fMRI) to measure the effect of haptic-visual cross-modal priming have found that the occipital cortex associated with visual processing mediates the neural processes underlying both visual and haptic object recognition [43-46]. The neurological overlapping of visual and haptic processing seems to indicate that the haptic system may be able to recruit the object representation systems of the ventral visual pathway [47, 48], an effect that has been observed in various studies that have investigated the neurological processes of visually impaired individuals.

An experiment by Bouaziz, Russier, and Magnan [49] revealed one of the potential impacts of neurocognitive 
plasticity between the visual and haptic processes. They investigated whether visual imagery was necessary to copy complex geometric shapes and that if so then blindfolded sighted children would be superior in the task to children who were blind. The drawing of complex shapes was explained to be the result of a graphic rule called the centripetal execution principle (CEP), copying from the outside shape to the inner shape [50], with the rationale that if vision were necessary then those individuals with blindness would not perform as well as their sighted counterparts.

The experiment conducted by Bouaziz and colleagues involved children who were sighted, low-vision, and blind. The children were asked to feel a raised-line drawing of a picture of geometric shapes entwined together and then copy it onto a sheet of their own raised-line drawing kit. The results were that both the groups of children who were sighted and blind had a dominant CEP, whereas the children in the low-vision group performed at a significantly lower level than the other children. However, there was not a significant difference between the children who were blind and sighted.

Bouaziz and colleagues interpreted the results as showing that both the children who were blind and the children who were sighted each had time to consolidate their respective modes of perceptual abilities. According to their interpretation, these results show that visual imagery was not necessary to process information of a visuospatial nature. The sighted children were assumed to have better developed visual representations that allowed them to interpret the raised-line drawing in a way that would reinforce those visual representations; whereas the children who were blind had better specialized haptic representations that would allow them to interpret the drawing in a way that would best suit their abilities. The low-vision children however, seemed to have greater difficulty in copying the images.

There are varying reasons as to why this would be the case, Bouaziz and colleagues suggest that low-vision participants were having trouble organizing the two systems, vision and haptics, to work together efficiently. In accordance with this theory, it is possible that the low-vision participants misappropriated much of their cognitive resources to visual processing when they would have been more efficiently employed in haptic processes. Individuals that are visually impaired (but not blind) will primarily use vision to determine size and shape, just as the sighted population would, when it may be more effective to employ haptic processes to a greater degree. The study by Bouaziz and colleagues [49], and many others [see reviews in 51,52] show a definite link between some higher symbolic/cognitive processes (i.e. drawing) based on haptics and the underlying visual-somatosensory plasticity in the cerebral cortex of individuals with early total blindness.

Haptic drawings can be made by marking a plastic sheet of paper (for example Mylar plastic sheets), resulting in raised lines on the same side of the paper that can be felt by hand. Congenitally totally blind children spontaneously draw meaningful representations of 3D objects without being taught pictorial conventions, without extensive practice in drawing, and without extensive exposure to pictures (See Fig. (1) for some examples) [37]. Many commonalities have been discovered in the way congenitally blind and sighted individuals depict 3D objects using raised-line drawings [51].

Because drawing partly depends on perceptual memory [53], it is plausible that drawings of concrete objects represent some of the perceptual principles that overlap in haptics and vision, since drawing is a physical activity of the hands, governed by feedback between hands, brain and eye, drawing must of necessity be an output that is compatible with both system's internal structure and can be similarly represented and stored in memory. Properties that are perceived by the haptic system may therefore be sufficient for recognition of haptic drawings, and enhanced tactile memory in early blind persons may compensate for lack of vision. This is possible because the brain can use some deep similar structural descriptions of the 3D world as 2D sketches or schemata both in vision and haptics. Therefore, not just sighted people can turn these descriptions into drawings, blind people can do it similarly even though they cannot see angles, corners, etc. Because of this overlap, the brain can hijack the function of the visual cortex to support haptic drawing in blind individuals and the resulting drawings make sense to sighted observers.

Consequently, cross-modal plasticity can explain the developmental trends manifested in the drawing production
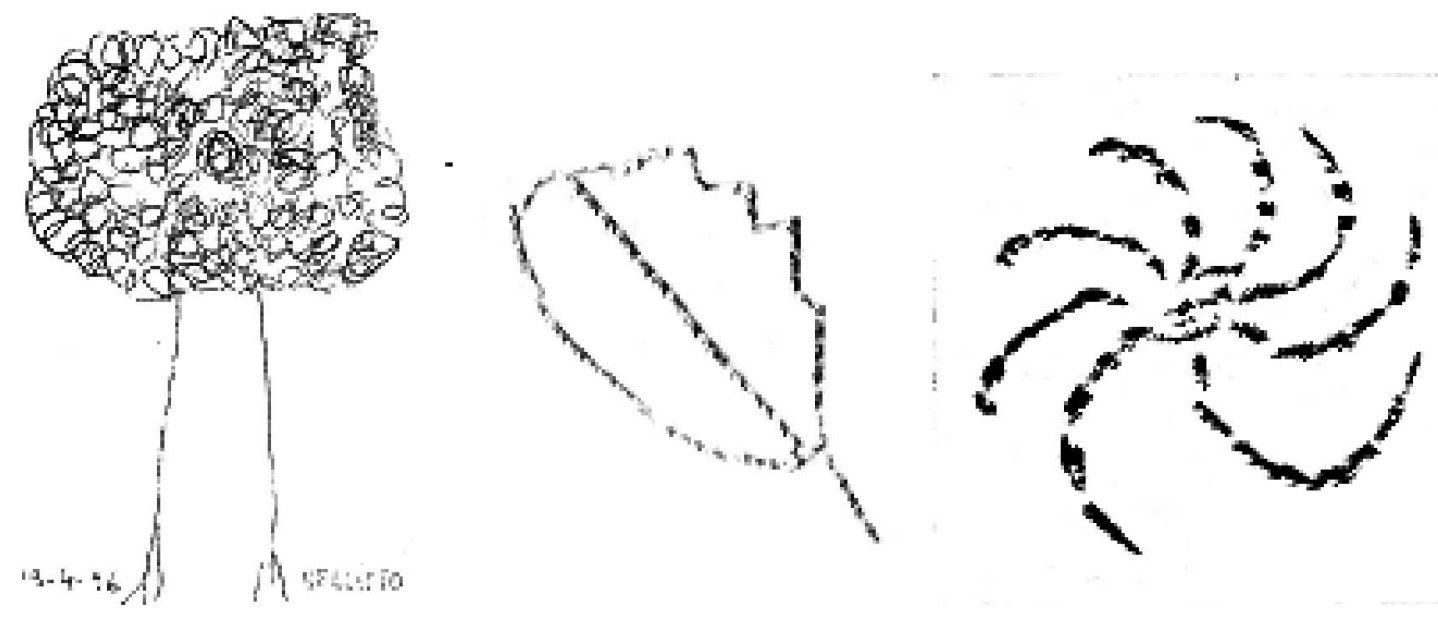

Fig. (1). Raised-line drawing of a tree, a leaf and a spinning wheel by three different 12 -year old congenitally blind children. 
by early totally blind children and adults. Congenitally blind children are surprisingly creative given that they cannot see what they are describing and have no visual "models" to copy [37]. If cross-modal plasticity is responsible for sharpened sensory discrimination and perceptual learning, it is then possible that the enhancement of tactile skills could also underlie much of the ability and self-motivation in developing haptic graphic symbols to represent in $2 \mathrm{D}$ the connections between what is perceived and what is known about perceived objects in 3D. The question is how exactly cross-modal plasticity could be the by product biological mechanism underlying the counterintuitive creativity shown in blind individuals' drawings. Next, we turn to considering this central question in much more detail.

\section{CROSS-MODAL PLASTICITY AND CREATIVITY IN HAPTIC DRAWING}

So far we have been tacitly implying a general and relatively uncontroversial notion of creativity, namely, "the ability to produce work that is novel (i.e., original, unexpected), high in quality, and appropriate (i.e., useful, meets task constraints)" [54; p. 1]. One activity that meets the criteria for this definition of creativity is the production of drawings and consumption of pictures in individuals who are blind. That a child born completely blind can make and appreciate the equivalent of outline pictures, which can be readily understood with visual inspection and are appropriate for a host of purposes (e.g., help communicating with teachers/parents, aesthetic pleasure, play, etc.) continues to puzzle many, including the writers. Indeed, creativity has been one of the earliest motivations for and approaches to the investigation of this form of higher symbolic activity in children and adults [i.e., discussions and reviews in 7,31].

However, if in doubt about the connection between creativity and haptic drawing in individuals who are blind, one should consider Fig. (2). This is the self-portrait of a completely blind boy who lost his residual vision early in life, and who discovered Leonardo's grid virtually by himself, with minimal tuition from a teacher. Figs. $(\mathbf{3}, \mathbf{4})$ show other examples of drawings made by the same child. It is intuitive that, in some sense, pictorial consumption and haptic drawing in blindness implies going beyond some expected limitations, behavioural, perceptual, and cognitive, and like most observable products of creativity this one tells something about extending human potential.

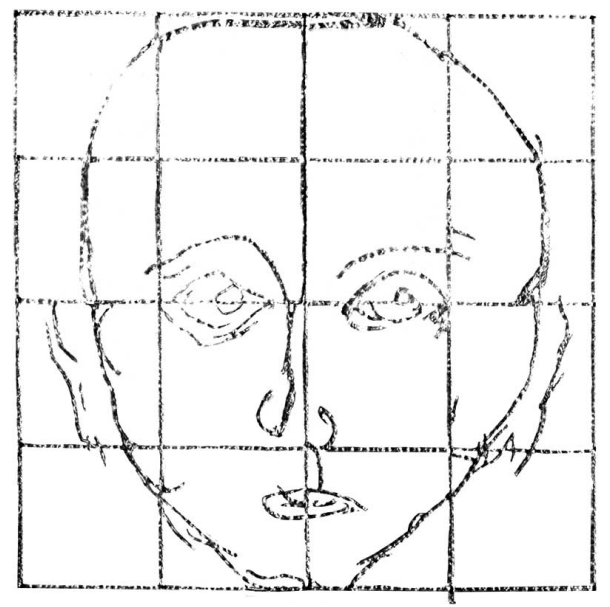

Fig. (2). "Self-portrait" by a 12 year -old early blind child.
Beyond intuition, there is a sense in which haptic picture consumption and drawing in blindness literally presupposes what we may call neurophysiological creativity. That is, the ability of going beyond a prescribed neural organization and the ability of developing some other new forms of neural organization. In the particular case of early or congenital blindness, the process is most commonly known as crossmodal compensatory plasticity. Namely, the activation by auditory or somatosensory stimuli of brain regions designed for the processing of vision shows the tremendous plasticity of the brain in adapting to changes in its internal environment [55].

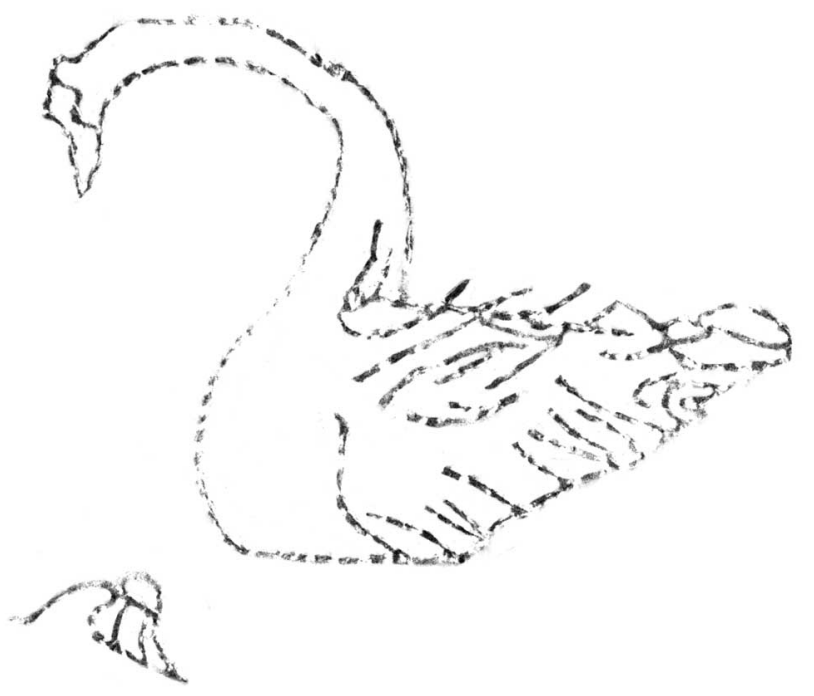

Fig. (3). "Swan" by a 12 year -old early blind child.

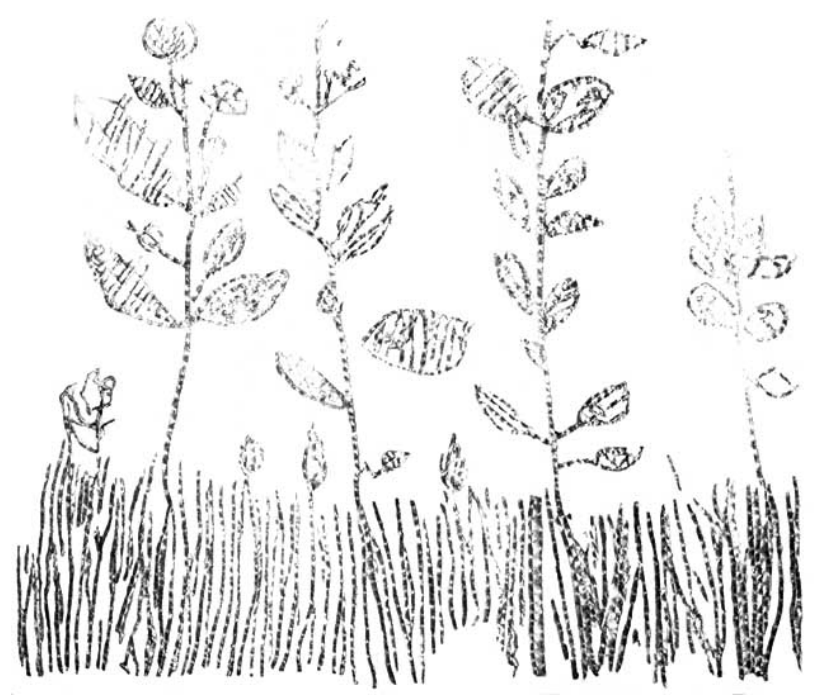

Fig. (4). "Field" by a 12 year -old early blind child.

Thus, the study of haptic drawing in blind individuals, especially congenitally totally blind children, essentially is another way of investigating the biological and developmental basis of creativity. If it can be convincingly defended, on the basis of the evidence discussed so far, that blind children can draw meaningful graphic symbols, without being taught pictorial conventions, without extensive practice in drawing, and without extensive exposure to pictures, then again cross-modal plasticity can explain the 
products of this novel, appropriate and high-level symbolic activity. Because cross-modal plasticity may be responsible for enhanced perceptual learning and cognitive skills [41, 56], it is then possible that the enhancement of haptic skills could also underlie much of the ability to develop the symbols that describe the connections between what is perceived and what is known about objects, and this would be the specific locus of the creative generativity shown in blind children's and adults' drawings.

\section{PERCEPTUAL FOUNDATIONS OF CREATIVITY IN HAPTICS AND VISION}

It is easy to see how it is possible to use the understanding of haptic drawing to understand the possible foundations of creativity in haptics. Traditionally, the study of haptic drawing in blindness has served the purpose to answer questions on the relationships between sensory input modalities, perceptual and mental representations, such as mental imagery, with the purpose of generalizing the answers to haptics in general $[12,22,52]$. As an example, consider Fig. (5).

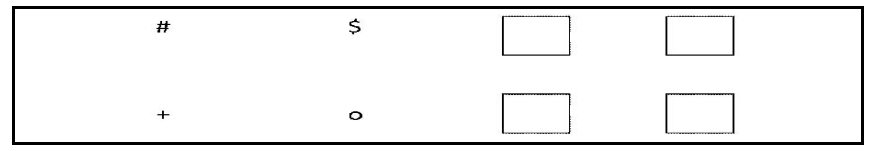

Fig. (5). Two gestalts of "square" that stimulate the retina in a completely different way.

Fig. (5) shows a classic puzzle in the study of human visual as well as haptic perception; it shows two groups of symbols composed by four elements. Both configurations can be visually grouped and interpreted as a "square", in spite of the fact that they are composed of quite different elements, and that they send two distinctly different configurations of sensory input to the retina. One set of the questions that has puzzled psychologists and philosophers for centuries is the following: Is the "squareness" perceived in Fig. (5) unimodal - that is, specific to one particular modality (notably, vision)? Is it related to two or more interdependent modalities (i.e., vision \& proprioception, for example via eye movements)? Or is it amodal/abstract knowledge superimposed to whatever sensory input that reaches the receptors (i.e., retina)?

Interestingly, the best way to frame these questions is to consider them from the perspective of blindness and haptic perception, not visual perception. If the perceptual representations of the squareness perceived in Fig. (5) are unimodal that implies that blind individuals should have no way to recognize things like pictures, just because they should not perceive a square, say, by touching four Braille dots, in the same way as sighted individuals would by looking at either of the visual configurations shown in the figure. If instead perceptual representations are cross-modal, then blind individuals should probably recognize some aspects of the square via touch, specifically they will apprehend those aspects of Braille dots that translate their cognition of surfaces or three-dimensional (3D) objects having a square or rectangular structure (e.g., a monitor). Yet, if perceptual representations were amodal, blind individuals would have an abstract notion of how squares and cubes appear in pictures (e.g., perspective, contour, shape) via touch.
Fig. (6) graphically shows the processes underlying unimodal, inter-modal (cognitive) and amodal representations; although the terminology has been modified, this conceptualization is due to Kanizsa [57].

In Fig. (6a), the chain ring is completely specified in features present in the visual modality; there is nothing more or less of the information given. In Fig. (6c), however, two central areas of the ring are missing. If "mentally interpolated" by the observer, it is still possible to mentally integrate or complete the two interrupted arches as one ring. However, this integration is again a mental representation and is not perceived, what is perceived are always two arches separated in a white background. The most interesting case for us is displayed in Fig. (6b). In the latter figure, although the two arches are still detached they are "seen" as completing in a ring behind a white bar. The completion behind the bar is not actually perceived through any modality, it does not exist in the retina but still it is perceived as vividly as if it was actually seen.

In terms of underlying brain processes, the unimodal representation implies that, for instance, if the visual cortex is impaired from birth there is no possibility to process pictures. Cross-modal representation implies that visual areas may be recruited to enhance perceptual learning, hence, pictorial processing in other modalities, e.g., in touch. For example, sensory-motor processing is augmented in that it "invades" visual association areas. Amodal representation implies that there is a discrete location, an integrative centre, which interprets sensory input equivalently from different modalities. That is, touch can substitute vision or vice versa if one of these is impaired early in life or at birth (sensory substitution).

However, neuroimaging evidence shows that portions of the association visual cortex are recruited by early blind individuals to read Braille and perform tactual discrimination tasks $[58,59]$. The extrastriate visual cortex near the parietooccipital fissure is activated to carry out tactual tasks in sighted people (and mental imagery is usually reported) [43]. Although there are some differences between populations, during haptic tasks, blind individuals activate some of the same areas that are activated during mental imagery in sighted individuals [59]. Moreover, when primary somatosensory cortex is stimulated through transcranial magnetic pulses (TMS), texture, shape and orientation are impaired during tactile discrimination tasks; but when TMS is applied to the occipital cortex only shape and orientation are similarly affected [45].

Therefore, it can be concluded that overall the neuroimaging data seem to favour the idea that blind individuals use cross-modal processing and are also engaged in "integrative" cognitive processing to carry out haptic tasks. The integration seems very similar to what goes on during mental imagery in sighted people.

Other studies have suggested that there is a partial overlap of the mechanisms that determine perception in haptics and vision [60]. The partial overlap theory - which does not conflict with the concept of cross-modal plasticity argues that some principles of objective shape perception, from which pictorial representations are formed, are shared by both haptic and visual processing. There is a body of 


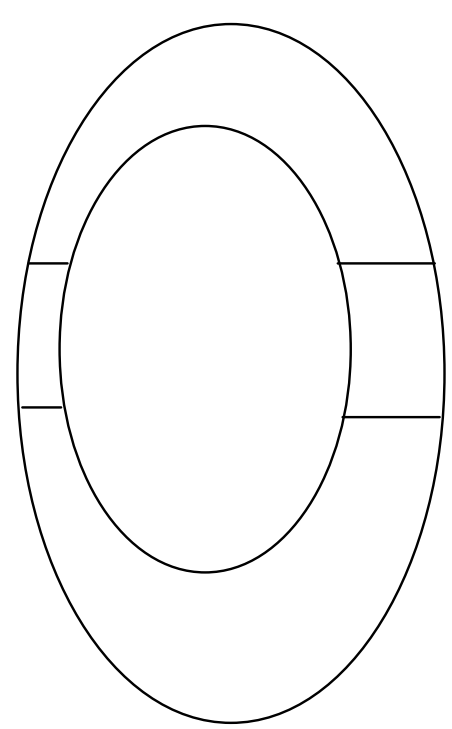

(a) Unimodal
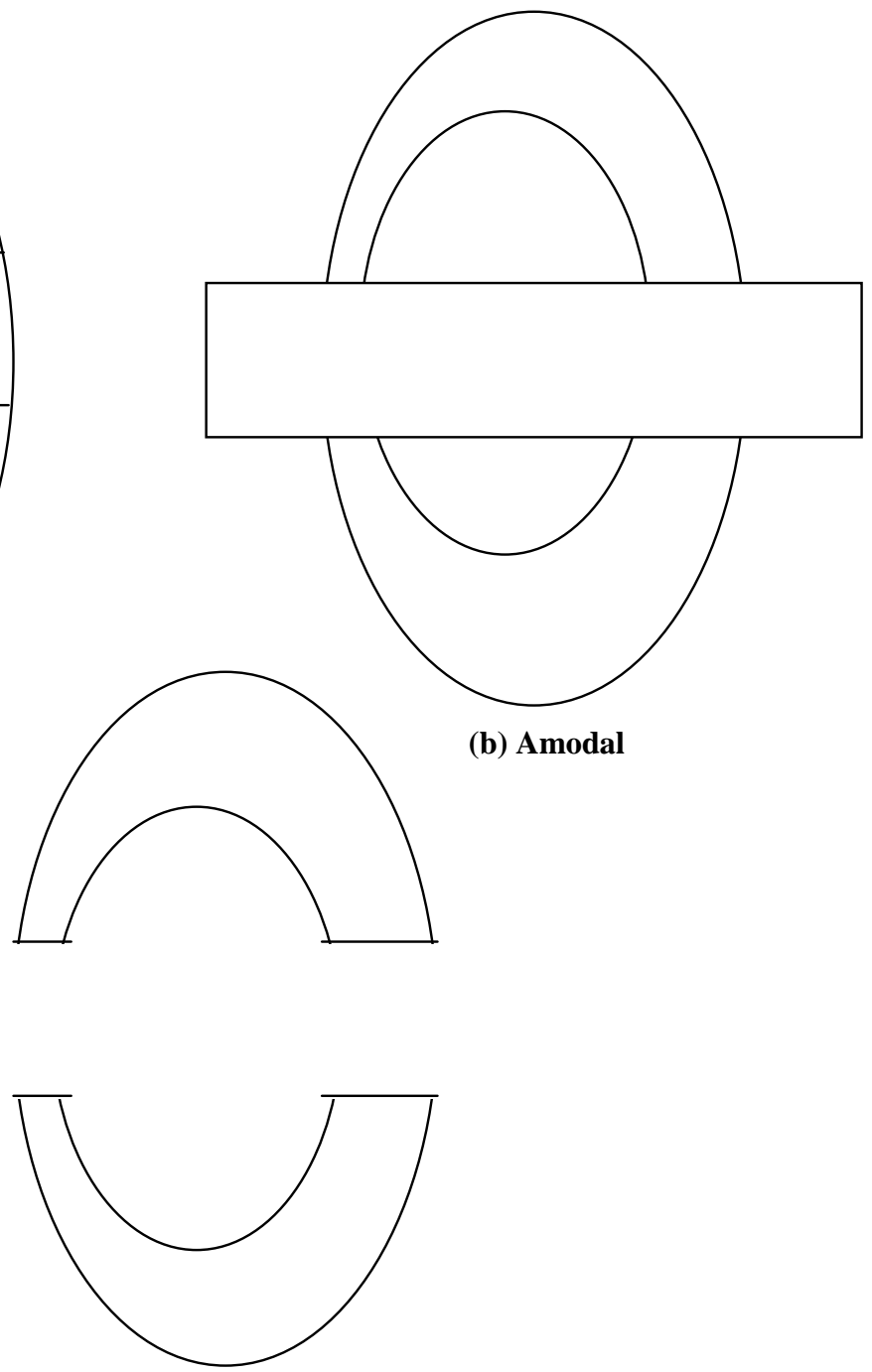

(c) Cognitive (Cross-modal)

Fig. (6). Examples of unimodal, inter-modal (cognitive) and amodal representations.

evidence that demonstrates blind individuals have an appreciation for and understanding of the principles of pictorial representation similar to sighted individuals [5]. It has been suggested in previous research that the similarities in haptic picture processing in blind individuals and sighted individuals may be a reflection of a partial overlap between representations of haptic and visual information [60]. As will be discussed in a later section, the overlap of haptic and visual representations may be a pathway by which individuals can go beyond the information given; furthermore, this overlap suggests ways in which both haptics and vision may support creative interpretation and use of inputs from the environment for the solution or the set-up of problems.

\section{INCLUSION}

For the blind and visually impaired, several benefits of implementing haptics into mainstream education are obvious. Haptics are the means by which the blind and those with severe visual impairments can participate in, and develop skills necessary for, activities that are conventionally thought to rely on sight. The extent of the development of haptic skills is at least partially determined by exposure to the materials, guidance, and experience. Therefore, the frequent opportunity for those with visual impairments to utilize haptic devices and materials will contribute to the development of haptic skills, which in turn will facilitate the construction of mental representations, likely via cross-modal plasticity.

As detailed in the previous section, the formation of these mental representations provides a foundation for creative expression. Thus, the implementation of haptic tools in mainstream education may allow blind and visually impaired individuals to partake in classes that would otherwise see them excluded, namely art class, and provide a creative outlet for expression. Furthermore, the inclusion of blind and visually impaired students in art classes that are predominantly composed of sighted individuals has been 
found to have positive effects on all involved, including the sighted students and teacher.

Pazienza [61] examined the mainstreaming of a young student with blindness into a fifth grade art class which proved to be an enlightening experience for the blind student, her sighted classmates, and even the teacher. Pazienza, an experienced art teacher, came into her first class of the year to discover a blind student, Dana, had been mainstreamed into her art class without forewarning. She was at a loss as to how to deal with the situation; she had no training for teaching children with blindness. Dana proved to be adept at using art materials such as, scissors, glue, and putting together the shapes she needed, which fascinated the other students of the class. Pazienza described the adjustments she had to make in terms of the words she used to describe materials as well as spending her time with each student, not neglecting anyone or hovering over Dana. When it came time for the students to present their art pieces to the class, there was some controversy over Dana's creation. Pazienza realised that her art work could not be judged solely on visual characteristics in terms of aesthetics. Upon this realisation, Pazienza told one student to come to the front, close their eyes and feel the art. At which point the student declared that he understood what Dana had attempted to convey through her use of the materials. It was with the culmination of this project that Pazienza realized there were small adjustments that had to be made to accommodate students with visual disabilities, but that they were not impossible to achieve and, most importantly, these modifications contributed to the enhancement of everyone's understanding of art.

Joanna Emmer [62] describes a similar experience with a non-visual art class at the college level that allowed individuals who were sighted as well as those who were blind to enrol. Those who were sighted were required to wear blindfolds or keep their eyes shut. The class was meant to involve senses other than vision, specifically hearing and touch. At the conclusion of the course, the blind students reported that they learned art was not as inaccessible as they perceived, they gained confidence and competence in their abilities to work with a variety of materials, and learned more about ways to create art, such as how to use "rules" pertaining to art. The sighted students reported that they learned more about what it must be like to have no vision, discovered a new way to communicate through art, and found their perception, in terms of what 'art' can be, opened up.

The experiences reported by Pazienza and Emmer illustrate some of the key benefits of including haptics in education for visually impaired and sighted populations. Haptics in education provide the means by which blind and visually impaired students have the opportunity to participate in classes that would otherwise see them excluded; whereas the non-visually impaired students are exposed to methods and strategies that can improve their understanding of visual disabilities. The students, both sighted and blind, who are given the opportunity to participate in haptic based classes are able to broaden their understanding of art and can develop skills that mediate their artistic and creative expression. It is in order here to mention one of the most widespread exercises in artistic drawing classes: "drawing without looking" or "blind contour drawing" [63]. This practice aims at perfecting one's skills in outline drawing by using haptics to follow the contours of the model accessed by vision and eye movements without looking at the paper. Not only has blind contour drawing been used in classrooms to help students develop hand-eye coordination, this form of drawing is also thought to assist in the student's ability to objectively observe and portray characteristics that do not necessarily conform to graphic conventions [64].

\section{HAPTICS, LEARNING AND REMEMBERING}

Haptics has not enjoyed the same amount of research as visual or auditory processing, as such haptics processing and how it may interact with other modalities is not completely understood. Nevertheless, various studies have shown that haptics can be extremely effective in facilitating learning and memory. In fact, in research that compared the processing of haptic, auditory, and visual stimuli, Kiphart, Auday, and Cross [65] proposed that the capacity of humans to process haptic information surpasses the capacity to process auditory or visual stimuli; a facility revealed by the failure to observe a rapid decay of information similar to those observed in visual and auditory short-term memory [62]. This lack of rapid decay of information from the haptic modality has been suggested to be due to the fact that haptic processing involves a system composed of several interrelated mechanisms that are not limited by a single receptor or sense organ $[3,65]$.

The haptic modality has not only been shown to have some potentially advantageous characteristics in terms of information processing; other studies have revealed that haptics may enhance performance on tasks that require the use of other sensory-modalities. A series of studies conducted by Bara, Gentaz, and Cole [66-68] have investigated the effect of using visuo-haptic exploration to help very young children learn the arbitrary association between alphabetical letters and their corresponding sound. As Fredembach, de Boisferon, and Gentaz note [69], it is generally agreed upon that reading acquisition involves two distinct processes: the development of orthographical and phonological representations; and the establishment of associations between these representations.

Reading training intervention conventionally adheres to the principle that letter and sound correspondences are an "implicit" process in which cross-modal associations are made [69-71]. Even though these kinds of reading training interventions are effective, they are generally very laborious, requiring several months of formal education before children can understand and apply alphabetical principles. Several studies have revealed that incorporating visuo-haptic exploration of relief cues facilitated both children and adults in learning how to make the association between novel visual and auditory stimuli [66-68].

Fredembach, de Boisferon, and Gentaz [69] point out two complementary theories that may explain the enhanced learning of cross-modal associations between sight and sound that occurred with the introduction of haptic cues. The first theory asserts that the addition of haptic information associating itself with the visual letters during the visuohaptic exploration stage enables multiple coding of the letter which could lead to an increase in memorization $[72,73]$ and 
recall $[69,74,75]$. The second theory proposes that the functional differences of the visual and auditory modalities can be "bonded" by corresponding haptic information. This theory rests on the premise that vision, characterized by its "quasi-simultaneity", is most suitable for processing visual stimuli; whereas listening, a necessarily sequential task, is most suitable for processing temporal stimuli [69]. This functional difference between the visual and auditory modalities may be responsible for some of the difficulty individuals experience when trying to make an association between visual and auditory stimuli. In contrast, haptic processing is both highly sequential, in terms of exploratory processes and encoding, as well as spatial, in the sense that haptic exploration can be distributed over concurrent parallel areas. Fredembach, de Boisferon, and Gentaz propose that:

"The sequential exploration generated by the incorporation of the haptic modality would lead children to process the letters in a more analytical way than when the letters were visually presented. Taken together, the visuohaptic exploration would help to build a link between the visual processing of the letter and the auditory processing of the corresponding sound; a "haptic bond effect"' [69, p.2].

These two theories explain the enhanced ability to form associations between visual and auditory stimuli by providing haptic cues and are also supportive of concepts proposed by other researchers. The concept discussed earlier, that multi-modal encoding can help individuals develop a global representation of a stimulus which may allow for a greater ease of encoding [76, 77], seems to encapsulate both of the theories suggested by Fredembach, de Boisferon, and Gentaz. Although the mechanism governing this facilitation effect is under debate, haptics remain a valuable educational tool. Haptic tasks have been shown to increase performance and overall comprehension in various subjects including language [69], art [62], science [78], and music [79].

\section{EDUCATIONAL IMPLICATIONS}

The development of strategies that define the efficacy of the somatosensory system to gather and organize information naturally occurs as an individual matures [20] and can be considered as extending across the life-span. The extent of this development is dependent on the amount of exposure, guidance, and practice that an individual has with haptic processes $[22,30]$; as such, it is not surprising that those who are blind are generally more apt at utilizing haptic procedures [22]. These findings indicate that educators have the opportunity to help pupils develop and optimize systematic and effective haptic strategies.

Furthermore, applying haptics processes has been found to facilitate the encoding and memorization of information and concepts $[65,76,77]$. From this, it is reasonable to conclude that conventional educational strategies could be improved for all populations with the addition of haptic tasks and instruction. Haptic drawing, in particular, could be generalized as a tool for inclusive education to promoting and enhancing creativity at any age by fostering cross-modal plasticity in students with and without visual impairments. Research supports the notion that blind individuals are able to recruit the visual cortex to process haptic stimuli, via cross-modal plasticity, and that all populations, regardless of being visually impaired or not, are capable of this transference of visual resources [43-46]. We suggest that the recruitment of these visual resources by haptic processes may be able to promote creativity and artistic growth within individuals.

Consideration of the partial overlap model previously discussed helps provide a concrete framework for how artistic growth and creative inspiration can be earned through the development of haptic skills.

(a)

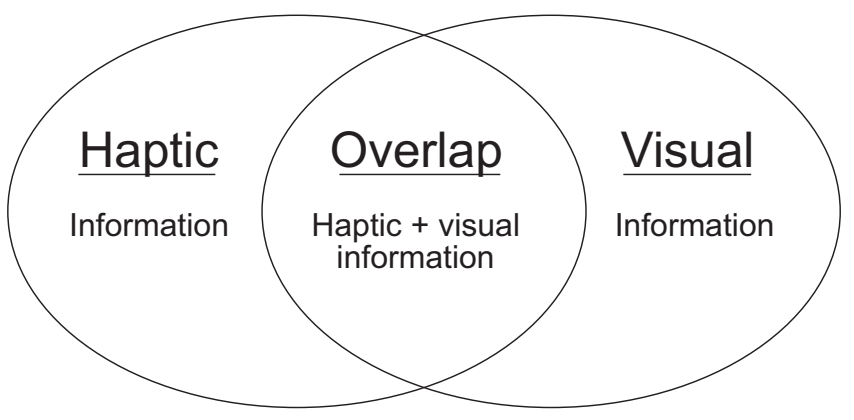

(b)

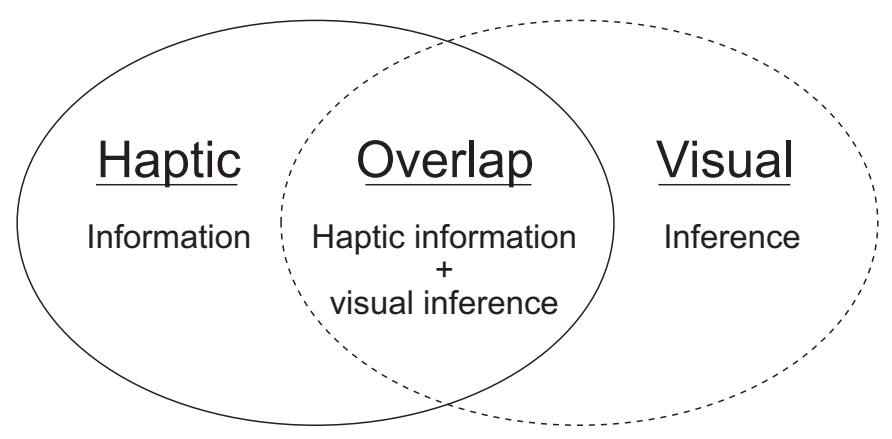

(c)

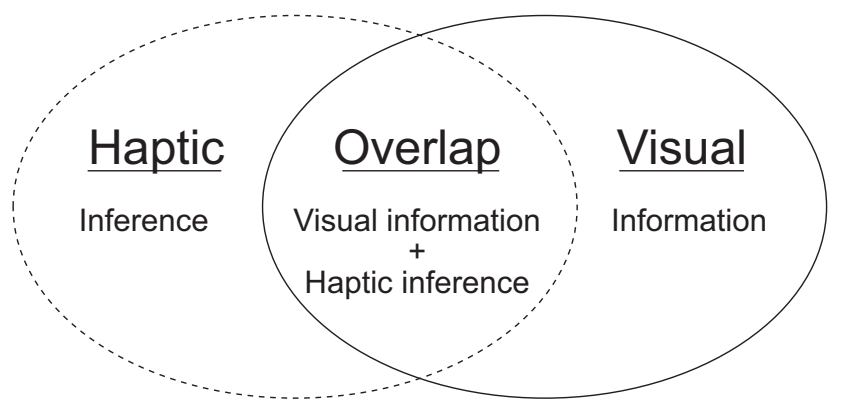

Fig. (7). Diagrams representing the partial-overlap model in three separate contexts.

Fig. (7) illustrates three distinct situations of sensory perception using the partial overlap model. Fig. (7a) represents a context where both haptic and visual encoding of stimuli is possible. In this situation, there are three operations to consider. Firstly, the perception of traits generally observed through the haptic modality alone, for example texture and weight, is informed by haptic exploration of the object itself; the visual modality is employed to generate an overall representation of the object without the need for sequential exploration, and it will also contribute specifically visual information to the 
representation of the object; and finally, both the haptic and visual modalities contribute to some aspects of the representation of the object, including the perception of size, surfaces, edges, motion, dimension, structure, and orientation $[3,45,60]$. In this example, each modality is providing sensory specific information, and simultaneously reinforcing information that overlaps with the other modality, all of which is contributing to the global representation of the object.

Fig. (7b) illustrates what blind individuals experience in their daily lives, when haptic information is available but no (or extremely limited) visual data is being observed. In this context, the haptic modality is essentially serving the same function as before, contributing sensory data to the representation of the object; however, the visual modality is not contributing sensory data. In this situation, in accordance with previous research [80], we propose that individuals can use the sensory data, encoded via the haptic modality, to draw inferences regarding visual attributes of the object which contribute to the mental representation.

Conversely, Fig. (7c) depicts a common context for sighted individuals, when visual processing is possible but haptic processing is not; for example, viewing something from a distance. The visual modality is engaged and informs the formation of a representation. Whereas, the haptic modality is not being directly employed to encode information; therefore inferences regarding physical attributes usually sensed through haptic exploration are made and contributed to the global representation of the stimulus. In each of these situations portrayed in Fig. (7) the degree by which each sensory modality is employed can be influenced by the recruiting of cognitive resources via cross-modal plasticity.

These three situations depict a paradigm in which the interaction between haptic and visual modalities can help promote creative works and concepts. For instance, a creative work that is composed by employing one primary modality can generate a synaesthetic representation in the other modality. Haptic data can generate a visual representation, and visual data can help generate a haptic representation. Specifically, for blind individuals, this means that what is conventionally known as visual art can be created using the haptic modality alone. For sighted individuals, where haptic and visual modalities are both available to recruit, the implication is that they can make use of the overlapping nature of haptic and visual representations to create artistic congruencies and contradictions. Imagine a work of art whose haptic representation contradicts its corresponding visual representation, or vice-versa, creating conflict and surprise in the audience; for example, something that feels like a plant but is gold in colour, or something that looks like coarse sandpaper but is smooth to the touch. Indeed, these "violations" have been shown to be sometimes the origins of metaphorical thinking implemented as graphical devices in drawing or figures of speech in language [51].

In the optimal situation, where both haptic and visual observation is possible as portrayed in Fig. (7a), the interaction between the two modalities can enhance the mental representation of the stimulus. This implies several potential applications in educational processes that would benefit from enhanced learning and memory; furthermore, the potential to enhance the mental representation of a stimulus by employing both the haptic and visual modalities could also contribute to creative expression. The sensoryspecific information and the overlapping information provided by both modalities could be utilized in combination to provide emphasis and depth to a mental representation. In other words, an individual who is able to depict something using both haptic and visual modalities has the opportunity to create a "vivid multimodal imagery", something that may be more meaningful and memorable than a creation that only makes use of a single modality. The paintings by Esref Armagan come handy here to exemplify what this means. The adaptive function of multimodal imagery is about the only explanation of how an illiterate congenitally totally blind artist such as Esref can produce vividly coloured albeit also haptic landscapes (http://www.armagan.com/paintings. asp), this is a literal rendition of the concept we are attempting to explain. Incidentally, the creation of vivid imagery has long been suggested as a correlate of our spontaneous reaction to perplexity, bafflement and lack of understanding right after we are faced with a difficult or novel problem and we need some kind of perceptual surrogate to aid us [81, 82]. Again, Esref's paintings exemplify the indirect route to creativity through haptics.

\section{CONCLUSIONS}

In summary, previous research supports the assertion that the implementation of the results of haptic studies into mainstream education could have several benefits (Fig. 8).

It would be appropriate to think of haptic activities, such as haptic drawing, not just as a tool for including individuals who are blind in the world of people who have sight, but more as a vehicle for the "inverse inclusion", that is, of people who have sight into the world of blind people who come to contact with the world only or mainly through haptics. An inclusive educational environment, where both sighted and visually impaired individuals have access to haptic learning material and are provided guidance with haptic strategies, would assist in the development of efficient haptic processing strategies.

Researchers have observed that haptic information is not subject to rapid decay [65], it may enhance performance on tasks that require the use of other sensory-modalities [6668 ], and it can increase performance on some memorization $[72,73]$ and recall tasks $[69,74,75]$. These characteristics of haptic processing suggest that individuals who are educated in haptic principles and have access to haptic materials may have several advantages pertinent to learning. Furthermore, on the basis of previous research, we propose that individuals experienced in haptic processing, whether visually impaired or not, would be able to employ their understanding of haptic principles to generate novel, creative works that may transcend the canonical repertoire of existing visual symbols and extend their aesthetic appeal to more than one modality.

A recent marketing experiment provides a useful example of the potential benefits that introducing haptics into education may yield. The S60 Volvo facebook marketing experiment (http://www.facebook.com/video/ video.php? $\mathrm{v}=179227625488$ ) had a blind artist (Esref 


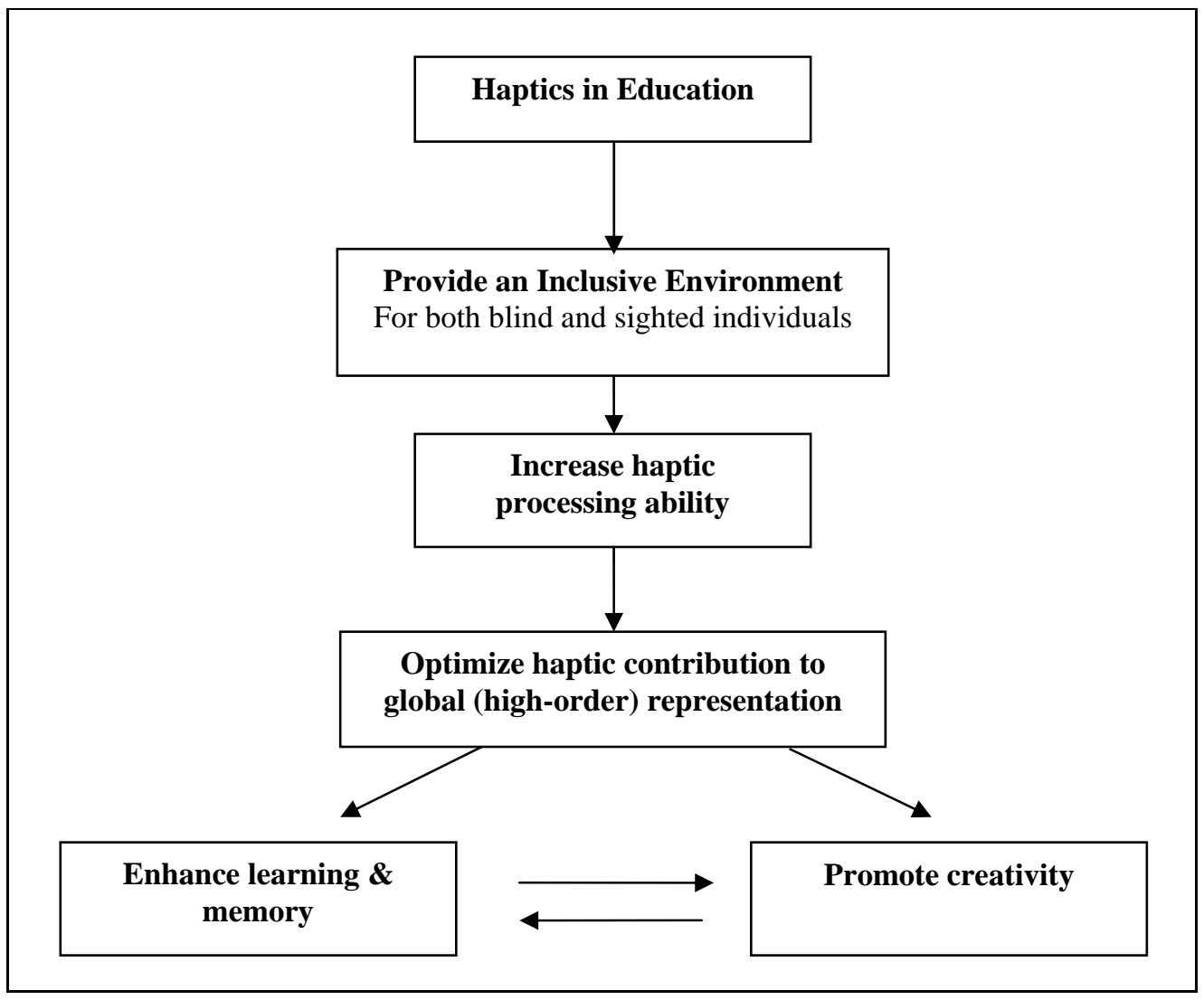

Fig. (8). A flow chart illustrating the proposed framework and potential benefits of implementing haptics into education.

Armagan) produce, on demand of sighted observers, haptic drawings of parts of a new model of a Volvo car (S60) that was never seen before, offering "blind previews" of the new car to sighted individuals through haptic drawings that can be seen and touched. The implicit metaphor of "double" inclusion is inescapable: Not only are sighted observers initiated to an imaginary content that pertains to the visual world, to which they are very well accustomed and familiar, but also they are introduced to a haptic world whose similarities and differences from their own experiences are pointed out by the creative activity of an "insider" artist. That is, in some way the sighted observers are for many aspects "blind" to the ways of haptics and are given a peak preview, a fragment of knowledge, of that set of unfamiliar experiences through overlapping aesthetic representations. In such a paradoxical circular way, creativity teaches something but it is also taught in a different modality. It is the task of future research and practice to take the Volvo marketing experiment as a lead model, and then systematically unleash and implement its unexploited, relatively untouched power in education contexts.

\section{ACKNOWLEDGEMENT}

None declared.

\section{CONFLICT OF INTEREST}

None declared.

\section{REFERENCES}

[1] McLaughlin M, Hespanha J, Sukhatme G. Touch in virtual environments: haptics and the design of interactive systems. Upper Saddle River, NJ: Prentice Hall 2002.
[2] Katz D. The world of touch. Krueger LE, Trans. Hillsdale, NJ: Lawrence Erlbaum 1989. (Original work published 1925).

[3] Minogue J, Jones MG. Haptics in education: Exploring an untapped sensory modality. Rev Educ Res 2006; 76(3), 317-48.

[4] Heller MA. Haptic perception in blind people. In: Heller MA, Schiff W, Eds. The psychology of touch. Hillside, NJ: Lawrence Erlbaum 1991; pp. 239-61.

[5] Lopes DMM. Art media and the sense modalities: tactile pictures. Philos Q 1997; 47(189): 425-40.

[6] Revesz G. The psychology and art of the blind. London: Longmans Green 1950.

[7] Arnheim R. Perceptual aspects of art for the blind. J Aesthet Educ 1990; 24: 57-65.

[8] Heller MA, McCarthy M, Clark A. Pattern perception and pictures for the blind. Psicologica 2005; 26: 161-71.

[9] Beck-Winchatz B, Ostro SJ. Using asteroid scale models in space science education for blind and visually impaired students. Astron Educ Rev 2004; 2: 118-26.

[10] Scadden L. Making mathematics and science accessible to blind students through technology. Proceeding of RESNA 1996 Annual Conference, Salt Lake City, UT 1996.

[11] Millar S. Visual experience or translation rules? Drawing the human figure by blind and sighted children. Perception 1975; 4(4): 363-71.

[12] Millar S. A reversed lag in the recognition and production of tactual drawings: theoretical implications for haptic coding. In: Heller MA, Schiff W, Eds. The psychology of touch Hillsdale. NJ: Lawrence Erlbaum Associates 1991; pp. 301-25.

[13] Bussell L. Haptic interfaces: Getting in touch with web-based learning. Educ Technol 2001; 41:27-32.

[14] Piaget J. The construction of reality in the child. New York: Basic Books 1954

[15] Piaget J, Inhelder B. The child's conception of space. New York: W. W. Norton 1967.

[16] Ruff, HA. Role of manipulation in infants' response to invariant properties of objects. Dev Psychol 1982; 18: 682-91.

[17] Streri A. Tactile discrimination of shape and intermodal transfer in 2- to 3-month-old infants. Br J Dev Psychol 1987; 5: 213-20. 
[18] Bushnell EW, Boudreau JP. The development of haptic perception during infancy. In Heller M, Schiff W, Eds. The psychology of touch Hillsdale, NJ: Lawrence Erlbaum 1991; pp. 139-161.

[19] Klatzky RL, Lederman SJ, Mankinen JM. Visual and haptic exploratory procedures in children's judgments about tool function. Infant Behav Dev 2005; 28: 240-9.

[20] Berger C, Hatwell Y. Development of analytic vs global processing in haptics: the perceptual and decisional determinants of classification skills. Br J Dev Psychol 1995; 13: 143-62.

[21] Lederman SJ, Klatzky RL. Hand movements: a window into haptic object recognition. Cogn Psychol 1987; 19: 342-68.

[22] Millar S. Modality and mind: Convergent active processing interrelated networks. A model of development and perception by touch. In: Heller MA, Ed. Touch, representation and blindness. Oxford: Oxford University Press 2000; pp. 99-141.

[23] Heller MA, Ed. Touch, representation, and blindness. Oxford: Oxford University Press 2000.

[24] Hochberg JE, Brooks V. Pictorial recognition as an unlearned ability. Am J Psychol 1962; 75; 624-8.

[25] Pring L, Walker J. Degree of accuracy in perceiving graphic and pictorial information by touch. Int J Rehab Res 1993; 16: 221-3.

[26] Pathak K, Pring L. Tactual picture recognition in congenitally blind and sighted children. Appl Cogn Psychol 1989; 3: 337-50.

[27] Shimizu Y, Saida S, Shimura H. Tactile pattern recognition by graphic display: Importance of 3-D information for haptic perception of familiar objects. Percept Psychophys 1993; 53: 43-8.

[28] D'Angiulli A, Kennedy JM, Heller MA. Blind children recognizing tactile pictures respond like sighted children given guidance in exploration. Scand J Psychol 1998; 39: 187-90.

[29] D’Angiulli A, Kennedy JM. Guided exploration enhances tactual picture recognition in blindfolded sighted children: implications for blind children. Int J Rehab Res 2000; 23: 319-20.

[30] Magee LE, Kennedy JM. Exploring pictures tactually. Nature 1980; 283: 287-8.

[31] Lowenfeld V. Creative and mental growth. $2^{\text {nd }}$ ed. New York: Macmillan 1952.

[32] Lev-Wiesel R, Aharoni S, Bar-David K. Self-figure drawing of born-blind adults: stages of artistic development and the expression of the senses. Arts Psychother 2002; 29(5): 253-9.

[33] Kennedy JM. Drawings from gaia, a blind girl. Perception 2003; 32(3): 321-40.

[34] Kennedy JM, Juricevic I. Haptics and projection: drawings by tracy, a blind adult. Perception 2003; 32: 1059-71.

[35] Kennedy JM, Juricevic I. Form, projection and pictures for the blind. In: Heller MA, Ballesteros S, Eds. Touch and blindness: psychology and neuroscience. London: Lawerence Erlbaum Associates 2006; pp. 73-93.

[36] D'Angiulli A, Maggi S. Development of drawing abilities in a distinct population: depiction of perceptual principles by three children with congenital total blindness. Int J Behav Dev 2003; 27(3): 193-200.

[37] D'Angiulli A, Miller C, Callaghan K. Structural equivalences are essential, pictorial conventions are not: evidence from haptic drawing development in children born completely blind. Psychol Aesthet Creat Arts 2008; 2(1): 20-33.

[38] Malchiodi CA. Understanding children's drawings. New York: Guilford 1998.

[39] Malchiodi CA, Kim DY, Choi WS. Developmental art therapy. In: Malchiodi CA, Ed. Handbook of art therapy. New York, NY: The Guilford Press 2003; pp. 93-105.

[40] Goldreich D, Kanics IM. Tactile acuity is enhanced in blindness. J Neurosci 2003; 23: 3439-3445.

[41] D'Angiulli A, Waraich P. Enhanced tactile encoding and memory recognition in congenital blindness. Int J Rehabil Res 2002; 25 : 143-5.

[42] Dulin D, Hatwell Y, Pylysyhn Z, Chokron S. Effects of peripheral and central visual impairment on mental imagery capacity. Neurosci Biobehav Rev 2008; 32: 1396-408.

[43] Sathian K, Zangaladze A, Hoffman J, Grafton S. Feeling with the mind's eye. Neuroreport 1997; 8: 3877-3881.

[44] Deibert E, Kraut M, Kremen S, Hart JJ. Neural pathways in tactile object recognition. Neurology 1999; 52: 1413-7.

[45] Zangaladze A, Epstein CM, Grafton ST, Sathian K. Involvement of visual cortex in tactile discrimination of orientation. Nature 1999; 401: 587-90.
[46] Amedi A, Malach R, Hendler T, Peled S, Zohary E. Visuo-haptic object related activation in the ventral visual pathway. Nature Neurosci 2002; 4: 324-30.

[47] Vanlierde A, De Volder AG, Wanet-Defalque MC, Veraart C. Occipito-parietal cortex activation during visuo-spatial imagery in early blind humans. Neuroimage 2003; 19: 698-709.

[48] Pietrini P, Furey ML, Ricciardi E, et al. Beyond sensory images: object-based representation in the human ventral pathway. Proc Natl Acad Sci 2004; 101: 5658-63.

[49] Bouaziz S, Russier S, Magnan A. The copying of complex geometric drawings by sighted and visually impaired children. J Vis Impair Blind 2005; 99(12): 765-74.

[50] Bouaziz S, Magnan A. Contribution of the visual perception and graphic production systems to the copying of complex geometrical drawings: a developmental study. Cogn Dev 2007; 22(1): 5-15.

[51] Kennedy JM. Drawing \& the blind: pictures to touch. New Haven, CT, US: Yale University Press 1993.

[52] Millar S. Understanding and representing space: theory and evidence from studies with blind and sighted children. New York: Oxford University Press 1994.

[53] Guerin F, Ska B, Belleville S. Cognitive processing of drawing abilities. Brain Cogn 1999; 40: 464-78.

[54] Sternberg RJ, Kaufman JC, Pretz JE. The creativity conundrum: A propulsion model of kinds of creative contributions. New York: Psychology Press 2002.

[55] Roder B, Rosler F. Compensatory plasticity as a consequence of sensory loss. In: Calvert G, Spence C, Stein BE, Eds. The handbooks of multisensory processes. MIT Press 2004.

[56] Sathian K. Practice makes perfect: sharper tactile perception in the blind. Neurology 2000; 54 (12): 2203-4.

[57] Kanizsa G. Vedere e pensare [Seeing and thinking]. Bologna: Il Mulino 1991.

[58] Sadato N, Pascual-Leone A, Grafman J, et al. Activation of the primary visual cortex by Braille reading in blind subjects. Nature 1996; 380: 526-8.

[59] Stilla R, Hanna R, Hu X, Mariola E, Deshpande G, Sathian K. Neural processing underlying tactile microspatial discrimination in the blind: A functional magnetic resonance imaging study. J Vis 2008; 8(10): 1-19.

[60] D'Angiulli A. Haptic pictures, blindness, and tactile beliefs: Preliminary analysis of a case study. The $28^{\text {th }}$ Annual Conference of the Cognitive Science Society, Vancouver: 2006. Retrieved 2011 March 31, from: http://csjarchive.cogsci.rpi.edu/proceedings/2006/ docs/p1174.pdf

[61] Pazienza J. Mainstreaming in art education: A case of the blind leading the blind. Art Educ 1984; 37(6); 20-1.

[62] Emmer J. Teach them to see: A non-visual art course. Coll Teach 1989; 37(1): 21-2.

[63] Nicolaides K. The natural way to draw. Boston, MA: Houghton Miffli 1941.

[64] Pariser DA. Two methods of teaching drawing skills. Stud Art Educ 1979; 20(3); 30-42.

[65] Kiphart MJ, Auday BC, Cross H. Short-term haptic memory for three dimensional objects. Percept Motor Skills 1988; 66; 79-91.

[66] Bara F, Gentaz E, Cole P. The visuo-haptic and haptic exploration increases the decoding level of children coming from lowsocioeconomic status families. Br J Dev Psychol 2007; 25: 643-63.

[67] Bara F, Gentaz E, Cole P, Sprenger-Charolles L. The visuo-haptic and haptic exploration of letters increases the kindergartenchildren's reading acquisition. Cogn Dev 2004; 19: 433-49.

[68] Gentaz E, Cole P, Bara F. Evaluation d'entraînements multisensoriels de pre'paration a' la lecture pour les enfants de grande section de maternelle. L'Année Psychologique 2003; 104 : 561-84.

[69] Fredembach B, de Boisferon AH, Gentaz E. Learning of arbitrary association between visual and auditory novel stimuli in adults: The "bond effect" of haptic exploration. PLoS ONE 2009; 4(3): e4844. doi:10.1371/journal.pone.0004844

[70] Bus AG, Van Ijzendoorn MH. Phonological awareness and early reading: A meta-analysis of experimental training studies. J Educ Psychol 1999; 91: 403-14.

[71] Byrne B, Fielding-Barnsley R. Evaluation of a program to teach phonemic awareness to young children. J Educ Psychol 1991; 83: 451-5.

[72] Hulme C. The interaction of visual and motor memory for graphic forms following tracing. Q J Expl Psychol 1979; 31: 249-61. 
[73] Hulme C. Reading retardation and multisensory teaching. London: Routledge \& Kegan Paul 1981.

[74] Chao LL, Martin A. Representation of manipulable man-made objects in the dorsal stream. Neuroimage 2000; 12: 478-84.

[75] Longcamp M, Boucard C, Gilhodes JC, et al. Learning through hand-or typewriting influences visual recognition of new graphic shapes: Behavioral and functional imaging evidence. J Cogn Neurosci 2008; 20: 802-15.

[76] Klatzky RL, Lederman S, Reed C. There's more to touch than meets the eye: The salience of object attributes for haptics with and without vision. J Exp Psychol: General 1987; 116: 356-69.

[77] Klatzky RL, Lederman SJ. The intelligent hand. In: Bower GH, Ed. The psychology of learning and motivation. San Diego, CA: Academic Press 1987; vol. 21; pp. 121-51.
[78] Brooks FP, Ouh-Young M, Batter JJ, Kilpatrick PJ. Project GROPE: Haptic displays for scientific visualization. ACM Comp Graphics 1990; 24: 177-85.

[79] Chafe C, O'Modhrain S. Musical muscle memory and the haptic display of performance nuance. CCRMA paper presented at the 1996 international computer music conference, Hong Kong; 1996. Retrieved 2011 March 3, from: https://ccrma.stanford.edu/files/pap ers/stanm99.pdf

[80] Hopkins R. Touching pictures. Br J Aesthet 2000; 40: 149-67.

[81] Betts GH. The Distribution and functions of mental imagery. New York: Columbia University, Teachers College Press 1909.

[82] Sheehan P. The function and nature of imagery. New York: Academic Press 1972.

(C) Kirby and D'Angiulli.; Licensee Bentham Open.

This is an open access article licensed under the terms of the Creative Commons Attribution Non-Commercial License (http://creativecommons.org/licenses/by-nc/ $3.0 /$ ) which permits unrestricted, non-commercial use, distribution and reproduction in any medium, provided the work is properly cited. 